\title{
Constraining global marine iron source and scavenging fluxes with GEOTRACES dissolved iron measurements in an ocean biogeochemical model
}

CHRISTOPHER SOMES ${ }^{1}$, ANDEW DALE ${ }^{1}$, KLAUS

WALLMANN $^{1}$, FLORIAN SCHOLZ ${ }^{1}$, WANXUAN YAO ${ }^{1}$, ANDREAS OSCHLIES $^{2}$, JUAN MUGLIA ${ }^{3}$, ANDREAS SCHMITTNER $^{4}$ AND ERIC P. ACHTERBERG ${ }^{1}$

${ }^{1}$ GEOMAR Helmholtz Centre for Ocean Research Kiel

${ }^{2}$ GEOMAR Helmholtz Center for Ocean Research Kiel

${ }^{3}$ Centro para el Estudio de los Sistemas Marinos CONICET

${ }^{4}$ Oregon State University

Presenting Author: csomes@geomar.de

Iron is a key micronutrient controlling phytoplankton growth in vast regions of the global ocean. Despite its importance, uncertainties remain high regarding external iron source fluxes and internal cycling on a global scale. In this study, we used a global dissolved iron dataset, including GEOTRACES measurements, to constrain source and scavenging fluxes in the marine iron component of a global ocean biogeochemical model. Our model simulations tested three key uncertainties: source inputs of atmospheric soluble iron deposition (varying from 1.4 $3.4 \mathrm{Gmol} / \mathrm{yr})$, reductive sedimentary iron release (14 - 117 $\mathrm{Gmol} / \mathrm{yr}$ ), and compare a variable ligand parameterization to a constant distribution. In each simulation, scavenging rates were adjusted to reproduce the observed global mean iron inventory for consistency. The apparent oxygen utilization term in the variable ligand parameterization significantly improved the model-data misfit, suggesting that heterotrophic bacteria are an important source of ligands to the ocean. Model simulations containing high source fluxes of atmospheric soluble iron deposition $(3.4 \mathrm{Gmol} / \mathrm{yr})$ and reductive sedimentary iron release (114 Gmol/yr) further improved the model, which then required high scavenging rates to maintain the observed iron inventory in these high source scenarios. Our model-data analysis suggests that the global marine iron cycle operates with high source fluxes and high scavenging rates, resulting in relatively short surface and global ocean mean residence times of 0.83 and 7.5 years, respectively, which are on the low-end of previous model estimates. Model biases and uncertainties remain high and are discussed to help improve global marine iron cycle models. 